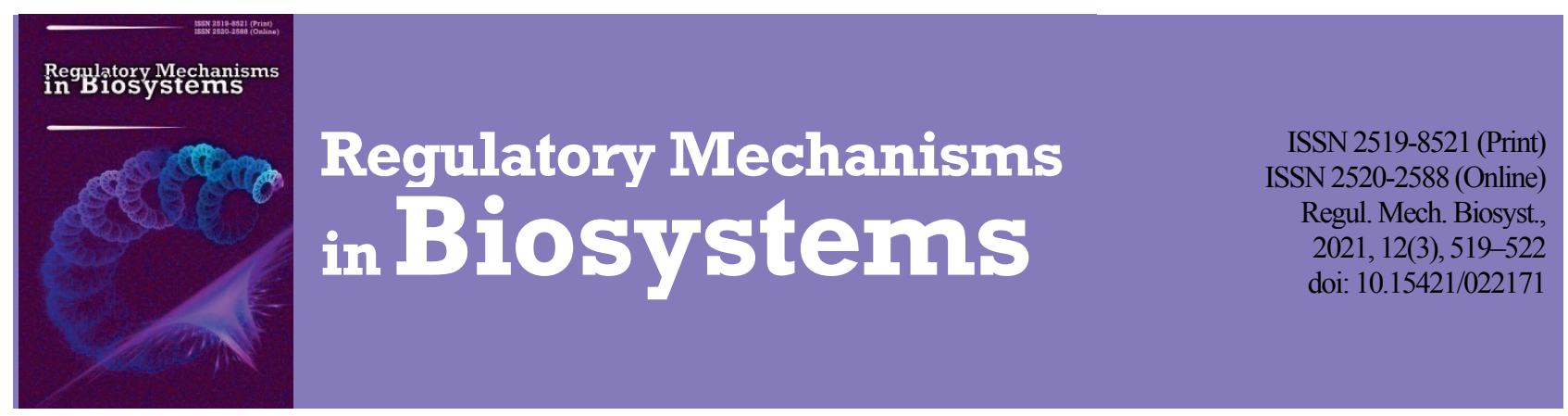

\title{
Proline content in the leaves of poplar and willow under water deficit
}

\author{
Y. A. Khoma*, O. G. Nesterenko*, N. K. Kutsokon*, L. V. Khudolieieva*, V. V. Shevchenko**, N. M. Rashydov* \\ *Institute of Cell Biology and Genetic Engineering, National Academy of Sciences of Ukraine, Kyiv, Ukraine \\ **Institute of Plant Physiology and Genetics of the National Academy of Sciences of Ukraine, Kyiv, Ukraine
}

Article info

Received 24.07.2021

Received in revised form 26.08 .2021

Accepted 29.08.2021

Institute of Cell Biology

and Genetic Engineering

National Academy

of Sciences of Ukraine,

Acad. Zabolotnogo, 148

Kyiv, 03143, Ukraine

Tel.: + 38-044-257-82-44.

E-mail:kutsokon@nas.gov.ua

Institute of Plant Physiology and Genetics of the National

Academy of Sciences

of Ukraine, Vasylkivska st., 31/17,

Kyiv, 03022, Ukraine

Tel.: +38-044-258-81-46.

E-mail:biochemkiev@ukr.net
Khoma, Y. A., Nesterenko, O. G., Kutsokon, N. K., Khudolieieva, L. V., Shevchenko, V. V., \& Rashydov, N. M. (2021). Proline content in the leaves of poplar and willow under water deficit. Regulatory Mechanisms in Biosystems, 12(3), 519-522. doi:10.15421/022171

Water deficiency is one of the most important abiotic factors limiting the growth and productivity of plants. Under conditions of water deficiency, plants can synthesize osmoprotectors, in particular proline. The aim of our work was to estimate the accumulation of free proline in the leaves of two poplar clones 'Slava Ukrainy', 'Guliver' and willow clone 'Pechalna' in water-deficient conditions. Plants were grown outdoors, providing protection from the rain with a plastic wrap, with a differentiated watering: normal watering $-100 \%$ (control) and water deficit $-75 \%, 50 \%$ and $25 \%$ moisture by volume from the control. The content of free proline was determined by a modified Bates method by measuring the optical density of the ninhydrin-proline solution on a spectrophotometer at a wavelength of $520 \mathrm{~nm}$. Experimental observations have shown that the total content of proline differs among poplar and willow clones. The poplar 'Guliver' had a lower content of proline compared to the poplar 'Slava Ukrainy' and the willow 'Pechalna'. The level of free proline also differed between the samples of poplar 'Guliver' in the first and second years of growth under water deficiency. However, on the 30th day of treatment we did not find any differences in the content of proline between the stressed and control plants. Thus, the clone factor has the only obvious effects on proline content while the factor of water regime showed no effects on the level of proline. We hypothesize that water deficiency is more likely to alter proline levels as a shorter time response to stress than the terms we applied.

Keywords: poplar; Populus; willow; Salix; water deficit; free proline; Bates method; abiotic stress.

\section{Introduction}

Fast-growing poplar and willow trees are plants belonging to the widespread Salicaceae family consisting of many species and play an important role in wood and biofuel production, public services, environmental protection, soil health, and afforestation of degraded soils (Kutsokon et al., 2017; Sklyarenko \& Bessonova, 2018). There is a great opportunity to realize economic and environmental benefits via creation of short-rotation plantations of these trees on land unsuitable for annual crop production. This will avoid public concern about the displacement of arable land from food to bioenergy production (Kharytonov et al., 2017; Kutsokon et al., 2020). In addition to its economic and environmental significance, the Populus genus is also a model for elucidating the physiological and molecular mechanisms of stress tolerance in tree species.

Water deficit is one of the most important abiotic factors that limit the growth, development, and productivity of woody plants (Chhin, 2016). Poplars and even more - willows - are usually sensitive to water scarcity. Differences in drought adaptation among the poplars are found at a variety of levels of organization, including the genetic, morphological, physiological, and biochemical responses of the plant (Guo et al., 2010).

Under conditions of water deficiency, plants can synthesize and accumulate various compounds, osmoprotectants, which play a major role in the osmotic adjustment of water deficit. Such compounds are some polyols, sugars and amino acids, and proline (Yadav et al., 2021). In poplar and willow, biochemical changes occur, including the accumulation of carbohydrates, secondary metabolites phytohormones, and proline (Bogeat-Triboulot et al., 2007; Jan et al., 2021). The accumulation of free proline in plant tissues occurs as a general reaction to water deficiency, salinity and other types of stress (Nasrin et al., 2016). It is known that in addition to the osmoprotective function, proline performs chaperone, anti- oxidant, signal-regulatory and other functions too (Sharma et al., 2019). Proline is an amino acid that combines the functions of a metabolite under stress, as well as a compound involved in the regulation of cellular processes. In addition, this amino acid performs a number of functions not related to the adaptation of plants to stress. In normal conditions, free proline (L-proline) is less than 5\% of the total amount of free amino acids in plants (Shahbaz et al., 2013). Accumulation of proline is considered one of the important signals for the transition to the flowering stage and is necessary for the development of pollen and seeds (Funck et al., 2012). In plants affected by various stressors, there is an increase in the concentration of free proline up to $80 \%$ (Shahbaz et al., 2013).

Signalling mechanisms inducing proline synthesis by abiotic stress in plants, primarily dehydration and salinization, include abscisic acid (ABA), calcium ions, reactive oxygen species (ROS), and possibly other signalling and hormonal mediators (Parkash \& Singh, 2020).

Proline is synthesized in two biochemical pathways in plants - from glutamate and ornithine, with regulation at two levels: enzyme activity and gene expression. It is believed that the synthesis of proline, induced by stress, occurs mainly by glutamate (Liang et al., 2013). The synthesis of proline from glutamate occurs in the cytosol and most likely in chloroplasts, due to the action of the bifunctional enzyme $\Delta 1$-pyrroline-5-carboxylate synthetase (P5CS) and $\Delta 1$-pyrroline-5-carboxylate reductase (P5CR) while the ornithine pathway is compartmentalized in mitochondria. P5CS in most plants is encoded by two genes and is represented by two molecular forms - P5CS1 and P5CS2, respectively. P5CS1 is localized in the cytoplasm and chloroplasts, P5CS2 - only in the cytoplasm. The level of proline synthesis is limited by the reaction that catalyzes P5CS. P5CR is encoded by a single gene in plants and is found in both the cytoplasm and chloroplasts (Szabados \& Savoure, 2010). Activation of glutamate biosynthesis and nitrogen fixation is required for sufficient ac- 
cumulation of proline in response to stress (Diaz et al., 2005). Degradation of proline occurs in mitochondria by sequential oxidation by proline dehydrogenase (PDH) to P5C (pyrroline-5-carboxylate), and then pyrroline5 carboxylate dehydrogenase (PCDH) to glutamate. The level of proline degradation is determined by the activity of PDH (Liang et al., 2013).

Due to the existence of at least two biochemical pathways, the control of proline synthesis is quite complex. There are many studies that have shown the feedback of proline biosynthesis with the final product, which acts as a reaction inhibitor. However, in stress conditions, this regulation is violated, and despite the high level of proline, its synthesis continues and may differ in intensity in various plant species (Székely et al., 2008).

Many studies have found a link between the accumulation of proline and the resistance of plants to stress, mostly when acute stress treatment was applied (Weiner et al., 2013; Didenko et al., 2016). However, there are opposite studies, when the amount of proline does not depend on the severity of stress, but depends on its duration. In particular, studies conducted by (Neither et al., 2020) on cacao leaves, showed a decrease in the amount of proline reaching almost control values during a long period (more than 21 days) of water stress. In addition, several studies have found that osmotically induced proline accumulation is not a prerequisite for tolerance to water stress, but a symptomatic disorder caused by dehydration (Larher et al., 2003). The experiments of Kocheva and Georgiev (2005) showed that after rehydration the level of proline in barley leaves under acute stress decreased to almost control values, which is probably due to its rapid metabolism and the complex interaction of proline with other stress-protective systems, particularly with antioxidant enzymes. There are different opinions in the literature about the role of free proline accumulated in plant tissues in response to stress. However, this amino acid can be considered as a marker of stress, which is one of its first signals.

Different genotypes of poplars and willows differ by their response to water stress, in particular by the synthesis of proline (Marron et al., 2002). Studying the accumulation of free proline in two clones of poplars and willow in water-deficient conditions is the aim of this study. It can be useful both for developing the approaches to assessing the plants' resistance to stress and for deeper understanding of the stress-protective functions of proline.

\section{Materials and methods}

Winter cuttings of two poplar clones 'Slava Ukrainy' (Populus nigra cv. 'Pyramidalis') and 'Guliver' (Populus $\times$ deltoides Marsh.) and willow clone 'Pechalna' (Salix alba $\times$ Salix fragilis) were collected at the plot of bioenergy plants at the National Botanical Garden of the National Academy of Sciences of Ukraine in Kyiv. The cuttings were kept in the fridge until planting in spring. The soil mixture consisted of black soil, peat and vermiculite (10:10:1.5), and each $1 \mathrm{~L}$ pot was filled with $1 \mathrm{~kg}$ of soil mixture. Pot plants (Fig. 1) were subjected to three water deficit regimes. Sufficient watering recognized as a normal field capacity served as a control. The control plants $(100 \%)$ were watered by $100 \mathrm{~mL}$ of water every other day or when needed. However, the frequency of watering mostly depended on the daily temperature. Experimental plants serving as three water deficit variants were irrigated at the same time, but one quarter $(75 \%)$, half $(50 \%)$ and three quarters $(25 \%)$ reductions in watering volume were applied. Three pots were used for each treatment and each pot contained two plants.
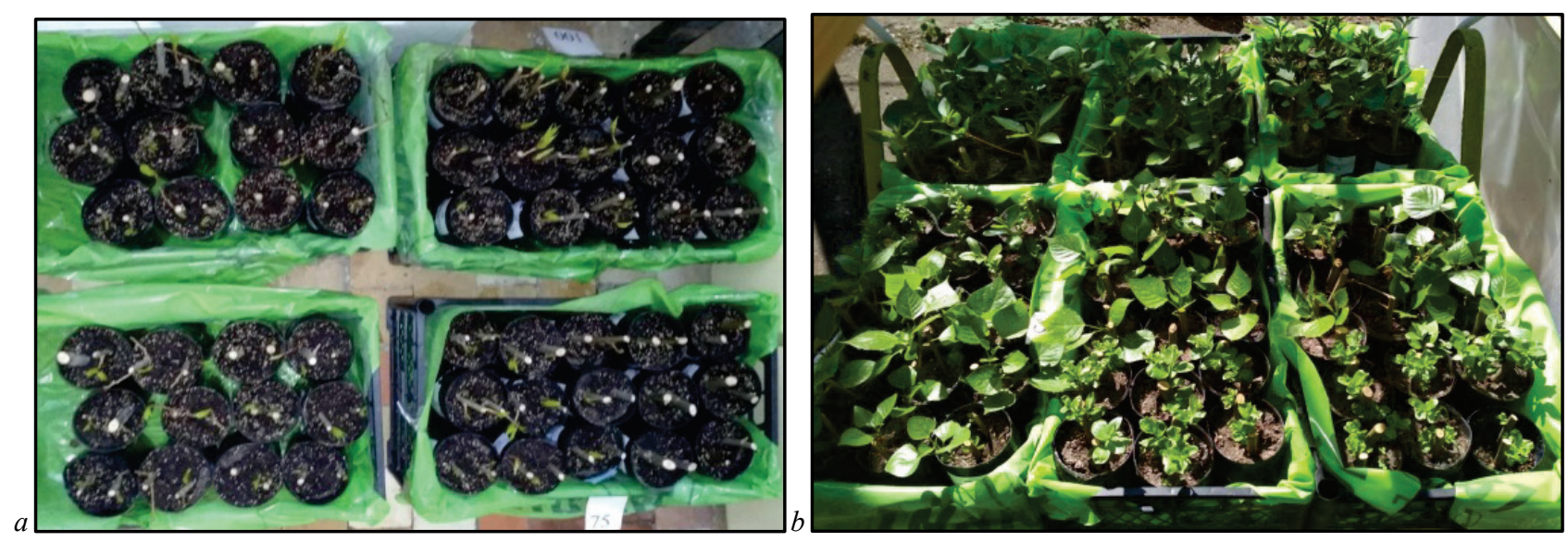

Fig. 1. Fast-growing trees (poplars 'Guliver', 'Slava Ukrainy' and willow 'Pechalna') planted in the pots: $a$-newly planted cuttings; $b$ - plants grown for 30 days, before differentiated watering

Throughout the growing season, the plants were kept outdoors, providing protection from the rain with a plastic wrap. During the rooting period, for 30 days, all plants were normally watered as needed. After 30 days, differential watering every 2-3 days was started. Measurements of growth parameters and collection of plant material to determine the content of proline were performed on 30th day after starting of differential watering. Simultaneously the same analyses were performed on second year plants of poplar clone 'Guliver' from a similar experiment conducted in the previous year, where differentiated watering was carried out throughout the previous growing season (from May to November). In November, the pots were transferred for winter storage in a cold room. During the dormant period, all plants were sufficiently watered when needed. In spring, the pots were transferred to an open air, and differential watering was resumed throughout the second growing season starting from the same time as the previously described clones. Thus, in both cases, plant material was collected at the same time - on 30th day after starting of differential watering.

To measure the content of proline, $200 \mathrm{mg}$ from at least three leaves was collected from each of up to six plants. The samples were frozen in liquid nitrogen, stored at $-40^{\circ} \mathrm{C}$ for biochemical analysis and four samples were used for proline determination for each variant. The content of free proline was determined by a modified Bates method using colorime- tric ninhydrin analysis (Carillo, P., \& Gibon, Y. Protocol: Extraction and determination of proline). $200 \mathrm{mg}$ of poplar and willow leaf samples were homogenized in $70 \%$ ethanol solution. After adding the reaction solution (ninhydrin 1\% (w/v) in acetic acid 60\% (v/v), ethanol 20\% (v/v), the mixture was incubated in a boiling water bath for 30 minutes. The tubes were then rapidly cooled to stop the reaction, centrifuged, and the optical density of the ninhydrin-proline solution was determined on a spectrophotometer (Specord 200, Analitik Jena, Germany) at a wavelength of $520 \mathrm{~nm}$.

The amount of L-proline was determined with the calibration curves of standard solutions with a concentration $1-80 \mu \mathrm{g} / \mathrm{mL}$ in the same reaction mixture of ninhydrin, acetic acid and ethanol (Fig. 2).

Statistical processing of the results was performed according to the common methods. Data are presented as the mean value \pm standard error of the mean $(x \pm S E)$. Data normality and variance homogeneity were checked with the Shapiro-Wilk and Levene tests, respectively. To determine tree clones/age and watering effects, two-way ANOVA was performed using the general linear model procedure (GLM) and the least significant difference (LSD) or the Tukey test as a post hoc test was applied. All tests were declared significant at $\mathrm{P}<0.05$. All statistical analyses and tests were performed with SPSS Statistics 23.0 software (IBM, USA). 


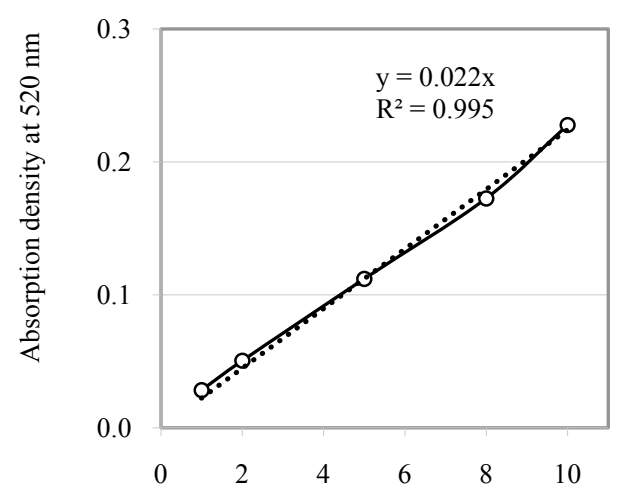

a

Proline concentration, $\mu \mathrm{g} / \mathrm{mL}$

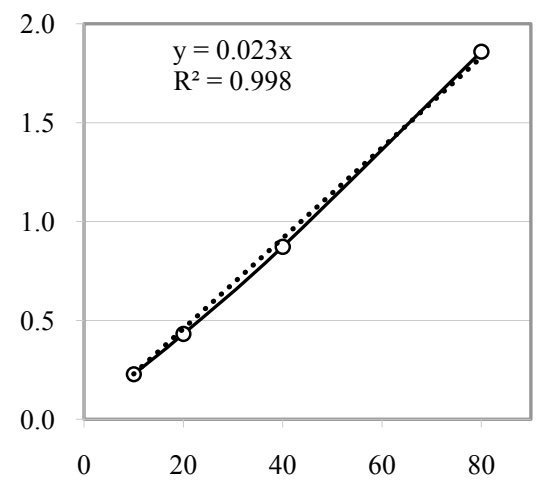

Proline concentration, $\mu \mathrm{g} / \mathrm{mL}$

Fig. 2. Calibration curves established over the concentration ranges of $1-10 \mu \mathrm{g} / \mathrm{mL}(a)$ and $10-80 \mu \mathrm{g} / \mathrm{mL}(b)$ : empirical curves were approximated with a linear trend $(\mathrm{P}<0.01)$

\section{Results}

Summarized results on the influence of the factor tree clones/age (poplars 'Slava Ukrainy' (first vegetation year) and 'Guliver' (first and second vegetation years) and willow clone 'Pechalna' (first vegetation year), and the factor of watering regimes $(100 \%$, and $75 \%, 50 \%$ and $25 \%$ of the control volume) on the free proline content are presented in Table 1. Clone and watering regimes were considered as fixed factors and were analysed in two-way ANOVAs.

Experimental observations showed that no differences in proline content were determined between different variants of watering (Table 1). But the total content of proline differs among the clones of poplars and willow as well as in the samples of the first and second year trees of poplar (Table 1). The lowest proline content was determined in the summarised (by different watering regimes) samples of poplar 'Guliver' in the second growing season which significantly differed from all other samples $(13.68 \mu \mathrm{g} / \mathrm{mL}, \mathrm{P}<0.05)$. The second lowest level of proline was found in the summarised samples of poplar 'Guliver' in the first growing season, which significantly differed from the samples of poplar 'Guliver' in the second growing season and the willow 'Pechalna' sample.

The effects of water regimes were also analysed separately for each clone and water regime. The differences between the clones within the same watering group after LSD test are presented in Figure 3. Significantly lower content of proline in the leaves of biennial plants of the clone 'Guliver' may indicate that proline content was decreased due to plant age under water stress in the previous growing year(Table 1, Fig. 3).
Table 1

The content of free proline $(\mu \mathrm{g} / \mathrm{mL})$ in the leaves of fast-growing trees $(\mathrm{n}=16)$ analysed in two-way ANOVA with factors: clone $\left(\mathrm{P}_{\text {clone }}\right)$, water regime $\left(\mathrm{P}_{\text {water }}\right)$ and the interactions of clones and water regimes $\left(\mathrm{P}_{\text {clone } \times \text { water }}\right)$

\begin{tabular}{|c|c|c|}
\hline Factor & Factor/Effect & $\begin{array}{l}\text { Proline content } \\
(\mathrm{x} \pm \mathrm{SE}), \mu \mathrm{g} / \mathrm{mL}\end{array}$ \\
\hline \multirow{5}{*}{ Clone (age) } & Poplar ‘Slava Ukrainy' (1 $1^{\text {st }}$ year $)$ & $18.68 \pm 0.76^{\mathrm{bc}}$ \\
\hline & Willow 'Pechalna' (1 $1^{\text {st }}$ year) & $19.95 \pm 0.81^{\mathrm{c}}$ \\
\hline & Poplar 'Guliver' (1 $1^{\text {\} } \text { year })} &{17.34 \pm 0.74^{b}} \\
{\hline} &{\text { Poplar 'Guliver' (2nd year) }} &{13.68 \pm 0.75^{\mathrm{a}}} \\
{\hline} &{P_{\text {clone }}} &{0.001} \\
{\hline \multirow{5}{*}{\text { Water regime }}\text { Water regime }} &{100 \%} &{17.70 \pm 1.16} \\
{\hline} &{75 \%} &{17.45 \pm 0.86} \\
{\hline} &{50 \%} &{19.16 \pm 0.92} \\
{\hline} &{25 \%} &{18.51 \pm 0.90} \\
{\hline} &{P_{\text {water }}} &{0.576} \\
{\hline \text { Clone } \times \text { water }} &{P_{\text {clone } \times \text { water }}} &{0.904} \\
$\hline
\end{tabular}

Note: ${ }^{a, b, c}$ - different letters indicate the significant differences within clone factors after LSD test $(\mathrm{P}<0.05)$.

Therefore, the basic and "under-stress" proline level was significantly lower in biennial plants of the clone 'Guliver' comparing to all other samples, and the highest proline level was determined in the willow 'Pechalna'. The clone factor has the only obvious effects on proline content while the factor of water regimes showed no effects on the level of proline.

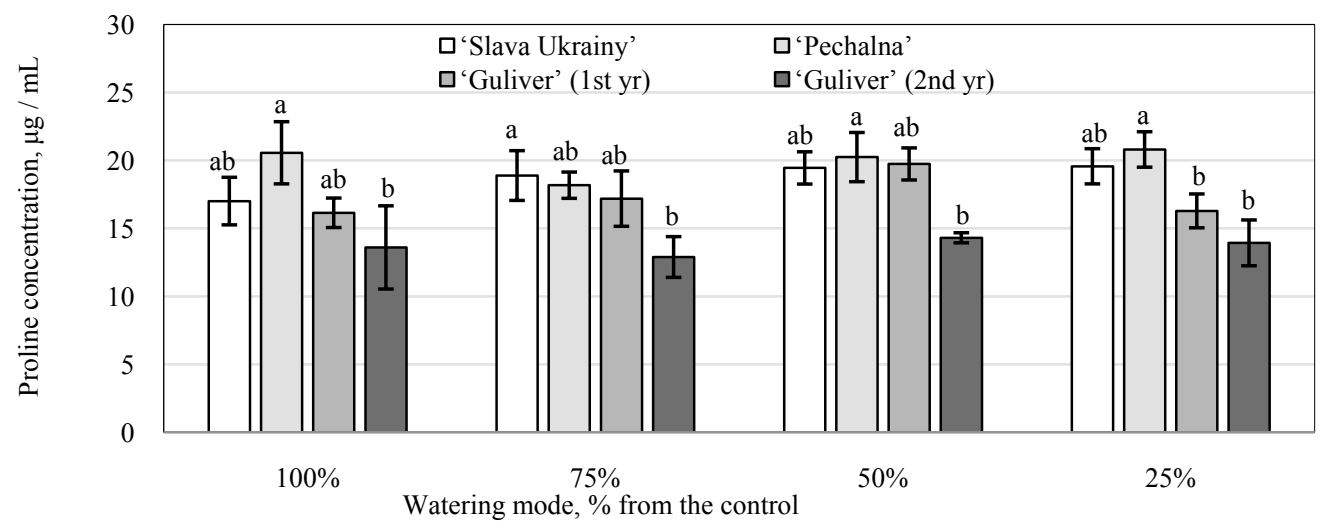

Fig. 3. Content of free proline ( $\mu \mathrm{g} / \mathrm{mL}, \mathrm{x} \pm \mathrm{SE}, \mathrm{n}=4)$ in the leaves of poplars (clones 'Guliver' and 'Slava Ukrainy') and willow (clone 'Pechalna') after 30 days of differential watering: $100 \%$ - control plants were watered normally, $75 \%, 50 \%$ and $25 \%$ - subsequent $\%$ of watering from the control volume; different letters above the bars denote significant differences between the clones within the same watering group after LSD test $(\mathrm{P}<0.05)$; no differences were found under different water regimes within the same clone

\section{Discussion}

From data obtained we, however, cannot determine exactly which plants have a better adaptation to water deficiency, or, in contrast, which are less adapted, as controversial opinions about the proline levels in stress condition exist in the scientific literature. Some studies of drought stressed plants demonstrated that the greater increment in free proline is the better drought tolerance. For instance, in the two poplar species, the amounts of free proline gradually increased as drought stress progressed, and the more tolerant clone had the higher proline rate (Yang \& Miao, 2010). In contrast, in our experiment severity of drought stress was not changed but kept at the same level in each clone for the whole term. Probably, stressed 
plants adapted their proline rates up to the control level in less than 30 days. Similar studies were conducted by Niether et al. (2020) on leaves of Theobroma cacao $\mathrm{L}$. when during prolonged drought stress (more than 21 days) the amount of proline decreased to control values. Diaz et al. (2005) in their studies on the leaves of Lotus japonicus, observed that the rate of proline accumulation was always higher during acute drought than during chronic drought. Perhaps this is due to rapid proline metabolism, or due to its complex interaction with other stress-protective systems, including antioxidant enzymes (Kocheva \& Georgiev, 2005; Parkash \& Singh, 2020).

It is known that about 20 genes are involved in the synthesis and degradation of proline in higher plants (Kavi Kishor et al., 2005), and the main genes, AtP5CS2 and AtP5CS1, are activated by low temperatures, drought, high salt concentrations, and osmotic stress. Their "switching on", "switching off" and cross-interaction at each stage of the plant response to stress can lead to fluctuations in the waves of synthesis and degradation of proline (Nesterenko \& Rashydov, 2018).

The amplitude of fluctuations in the content of proline depends on many factors. The concentration of this amino acid can sometimes increase ten to hundreds of times depending on the species of plant, the type of stress factor, the duration of its exposure and the time elapsed after the action of the factor. In particular, an increase in proline content was shown in millet after 30 minutes of stress exposure (Weiner et al., 2013), in Arabidopsis - in 4 hours during salt stress (Didenko et al., 2016), and in tobacco - in 7-10 days (Sergeeva \& Bronnikova, 2016). These different responses of genotypes may be associated with signalling cascades that regulate the proline metabolism, which are controlled by multiple cellular mechanisms and which should be further investigated (Bhaskara et al., 2015).

\section{Conclusions}

It was found that the content of free proline in the leaves of fastgrowing trees differed between the clones. Summarised data showed that the poplar 'Guliver' has significantly lower proline content compared to both poplar 'Slava Ukrainy' and willow 'Pechalna'. The level of proline was also different between the stressed tree samples from the first and second years of the poplar clone 'Gulliver'. Interestingly, the strength of water deficiency $(100 \%, 75 \%, 50 \%$ and $25 \%$ of control) did not affect the content of proline as was measured at the 30 th day of treatment. We hypothesize that water deficiency is more likely to alter proline levels as a shorter time response to stress than the terms we applied.

This work was carried out in the frame of the National Academy of Sciences of Ukraine program “Biofuel Resources and Bioenergy" (2017-2018 and 2019-2021), the state registration numbers $0118 \mathrm{U} 005379$ and $0120 \mathrm{U} 0002790)$. It was also supported by the National Research Foundation of Ukraine within the competition "Support for Research of Leading and Young Scientists", the project "Effects of stress factors on prion-like proteins synthesis in plants" (state registration number 0120U104870). The authors also are thankful to Prof. D. B. Rakhmetov, Deputy Director of M. M. Gryshko National Botanical Garden, NAS of Ukraine, for providing willow and poplars cuttings.

\section{References}

Bhaskara, G. B., Yang, T.-H., \& Verslues, P. E. (2015). Dynamic proline metabolism: Importance and regulation in water limited environments. Frontiers in Plant Science, 6, 1-7.

Bogeat-Triboulot, M. B., Brosché, M., Renaut, J., Jouve, L., Le Thiec, D., Fayyaz, P., \& Dreyer, E. (2006). Gradual soil water depletion results in reversible changes of gene expression, protein profiles, ecophysiology, and growth performance in Populus euphratica, a poplar growing in arid regions. Plant Physiology, 143(2), 876-892.

Chhin, S. (2016). Screening the resilience of short-rotation woody crops to climate change. Geosciences, 6(1), 7-14.

Díaz, P., Monza, J., \& Márquez, A. (2005). Drought and saline stress. In: Márquez, A. J. (Eds.). Lotus japonicus handbook. Springer, Dordrecht. Pp. 39-50.

Didenko, N., Volkov, R., \& Panchuk, I. (2016). Effects of saline stress on proline and polyphenolic compounds content in Arabidopsis thaliana. Biolohichni Systemy, 8(1), 35-39 (in Ukrainian).
Funck, D., Winter, G., Baumgarten, L., \& Forlani, G. (2012). Requirement of proline synthesis during Arabidopsis reproductive development. BMC Plant Biology, 12(1), 191-200.

Guo, X. Y., Zhang, X. S., \& Huang, Z. Y. (2010). Drought tolerance in three hybrid poplar clones submitted to different watering regimes. Journal of Plant Ecology, 3(2), 79-87.

Jan, R., Asaf, S., Numan, M., Lubna, \& Kim, K.-M. (2021). Plant secondary metabolite biosynthesis and transcriptional regulation in response to biotic and abiotic stress conditions. Agronomy, 11(5), 968-975.

Kavi Kishor, P., Sangam, S., Amruhta, R., Sri Laxmi, P., Naidu, K., Rao, K., Rao, S., Reddy, K., Theriappan, P., \& Sreenivasulu, N. (2005). Regulation of proline biosynthesis, degradation, uptake and transport in higher plants: Its implications in plant growth and abiotic stress tolerance. Current Science, 88(3), 424-436.

Kharytonov, M., Babenko, M., Martynova, N., Rula, I., Sbytna, M., \& Fuchilo, Y. (2017). The poplar saplings survival in reclaimed mineland depending on clone and root treatment. Agriculture and Forestry, 63(4), 3-8.

Kocheva, K., \& Georgiev, G. (2005). Assessment of solute accumulation in the leaves of barley seedlings under dehydration and rehydration. Comptes Rendus de l'Academie Bulgare des Sciences, 58, 421-426.

Kutsokon, N., Khudolieieva, L., Los, S., Torosova, L., \& Vysotska, N. (2020). Evaluation of poplar and willow clones on the experimental short rotation plantation in Kharkiv region: Results of the second cultivation year. Plant Varieties Studying and Protection, 16(2), 182-190 (in Ukrainian).

Kutsokon, N., Rakhmetov, D., Khudolieieva, L., Rakhmetova, S., \& Fishchenko, V. (2017). Growth characteristics and energy productivity of poplars and willows under short rotation planting for the first vegetation year. Biolohichni Systemy, 9(2), 238-246 (in Ukrainian).

Larher, F. R., Aziz, A., Gibon, Y., Trotel-Aziz, P., Sulpice, R., \& Bouchereau, A. (2003). An assessment of the physiological properties of the so-called compatible solutes using in vitro experiments with leaf discs. Plant Physiology and Biochemistry, 41, 657-666.

Liang, X., Zhang, L., Natarajan, S. K., \& Becker, D. F. (2013). Proline mechanisms of stress survival. Antioxidants and Redox Signaling, 19(9), 998-1011.

Marron, N., Delay, D., Petit, J.-M., Dreyer, E., Kahlem, G., Delmotte, F. M., \& Brignolas, F. (2002). Physiological traits of two Populus x euramericana clones, Luisa Avanzo and Dorskamp, during a water stress and re-watering cycle. Tree Physiology, 22(12), 849-858.

Nasrin, S., Hossain, M., Abdullah, M., Alam, R., Raqibul, M., Siddique, H., \& Saha, S. (2016). Salinity influence on survival, growth and nutrient distribution in different parts of Millettia pinnata seedlings. Agriculture and Forestry, 62(4), 161-173.

Nesterenko, O., \& Rashydov, N. (2018). Features of the proline synthesis of pea seedlings in depend of salt and hyperthermia treatment coupled with ionizing radiation. International Journal of Secondary Metabolite, 5(2), 94-108.

Niether, W., Glawe, A., Pfohl, K., Adamtey, N., Schneider, M., Karlovsky, P., \& Pawelzik, E. (2020). The effect of short-term vs. long-term soil moisture stress on the physiological response of three cacao (Theobroma cacao L.) cultivars. Plant Growth Regulation, 92(2), 295-306.

Parkash, V., \& Singh, S. (2020). A review on potential plant-based water stress indicators for vegetable crops. Sustainability, 12(10), 3945-3954.

Sergeeva, L., \& Bronnikova, L. (2016). Proline-mediated reactions of tobacco to the action of salinity. Scientific Bulletin of the Lesia Ukrainka East European National University, 12, 15-19 (in Ukrainian).

Shahbaz, M., Mushtaq, Z., Andaz, F., \& Masood, A. (2013). Does proline application ameliorate adverse effects of salt stress on growth, ions and photosynthetic ability of eggplant (Solanum melongena L.). Scientia Horticulturae, 164, 507-511.

Sharma, A., Shahzad, B., Kumar, V., Kohli, S. K., Sidhu, G. P. S., Bali, A. S., Zheng, B. (2019). Phytohormones regulate accumulation of osmolytes under abiotic stress. Biomolecules, 9(7), 285-293.

Sklyarenko, A. V., \& Bessonova, V. P. (2018). Accumulation of sulfur and glutathione in leaves of woody plants growing under the conditions of outdoor air pollution by sulfur dioxide. Biosystems Diversity, 26(4), 334-338.

Szabados, L., \& Savouré, A. (2010). Proline: A multifunctional amino acid. Trends in Plant Science, 15(2), 89-97.

Székely, G., Abraham, E., Cseplo, A., Rigó, G., Zsigmond, L., Csiszár, J., Ayaydin, F., Strizhov, N., Jásik, J., Schmelzer, E., Koncz, C., \& Szabados, L. (2008). Duplicated P5CS genes of Arabidopsis play distinct roles in stress regulation and developmental control of proline biosynthesis. The Plant Journal, 53(1), 11-28.

Weiner, A., Kolupaev, Y., \& Yastreb, T. (2013). Participation of hydrogen peroxide in induction of proline accumulation in millet plants under the action of $\mathrm{NaCl}$. Bulletin of Kharkiv National Agrarian University, Biology, 29, 32-38 (in Russian).

Yadav, B., Jogawat, A., Rahman, M. S., \& Narayan, O. P. (2021). Secondary metabolites in the drought stress tolerance of crop plants: A review. Gene Reports, 23, 110-140.

Yang, F., \& Miao, L. (2010). Adaptive responses to progressive drought stress in two poplar species originating from different altitudes. Silva Fennica, 44(1), 1-8. 